\title{
SIMULAÇÃO EM ALTA RESOLUÇÃO COM WRF UTILIZANDO A PARAMETRIZAÇÃO DE JANJIC NA BAIA DA ILHA DECEPTION
}

\author{
Alcimoni Nelci Comin ${ }^{1, *}$, Otavio Costa Acevedo ${ }^{1}$, Ronald Buss de Souza ${ }^{2}$ \\ ${ }^{1}$ Departamento de Física-Universidade Federal de Santa Maria (UFSM), RS, Brasil. \\ ${ }^{2}$ Centro Regional Sul de Pesquisas Espaciais - Instituto Nacional de Pesquisas Espaciais (INPE), Santa Maria, \\ RS, Brasil. \\ *alcimoni.comin@gmail.com
}

\begin{abstract}
The WRF model was run using the planetary boundary layer scheme from Janjic (2002), centered in the bay of Deception Island. The air temperature correlation was 0.95, while for the dew point temperature the correlation was 0.73 . The surface atmospheric pressure was the better represented variable, with a correlation of 0.99 . Finally, the wind intensity showed a lower correlation of 0.62 , with a greater tendency of the model to underestimate the observations.
\end{abstract}

\section{INTRODUÇÃO}

A Ilha Deception, com aproximadamente $15 \mathrm{~km}$ de diâmetro, apresenta uma configuração única, pois localiza-se em latitudes polares em cujo interior existe um lago com águas aquecidas por atividade geotermal. Assim, apesar de sua pequena extensão, os fortes gradientes térmicos entre o oceano e a atmosfera, têm potencial de produzir circulações locais bem definidas. Por outro lado, a localização em altas latitudes coloca a ilha na rota de sistemas sinóticos que ocorrem com grande intensidade. Desta forma, a combinação dos dois fatores, localização em altas latitudes e circulações locais intensas, permite caracterizar esta localidade como um laboratório real para testar a capacidade de modelo WRF (Weather Research and Forecasting) de reproduzir padrões meteorológicos em diversas escalas, de maneira simultânea.

O objetivo deste trabalho será de verificar o desempenho do modelo WRF em alta resolução, utilizando a parametrização proposta por Janjic (2002). 


\section{MATERIAIS E MÉTODOS}

Os dados reais utilizados neste trabalho foram medidos in situ, por sensores instalados em uma boia ancorada no interior da baia da ilha Deception, Antártica, durante o período 1 a 13 de novembro de 2012. Nas simulações, utilizaram-se três grades aninhadas, sendo que a mais interna teve resolução maior, de $500 \mathrm{~m}$ na horizontal, com 152 pontos em cada direção. A grade intermediária tinha 80 pontos com espaçamento de $1,5 \mathrm{~km}$ em cada direção e a grade mais externa consistia de 60 pontos em cada direção com $4,5 \mathrm{~km}$ de espaçamento. O motivo da diferença foi garantir uma boa representação da Ilha Deception. Para a entrada no modelo foram utilizados dados atmosféricos de Reanálise produzidos pelo NCEP (http://dss.ucar.edu) com formato GRIB2, com $1^{\circ}$ de resolução horizontal. Estas informações serviram como condições iniciais e de fronteira, que eram atualizadas a cada 6 horas. A modelagem do ciclo diurno CLP requer simulações precisas dos fluxos de calor, umidade e momento. Esses fluxos não são resolvidos em passos de tempo e, portanto, são parametrizados. As diferentes parametrizaçoes depende se os fluxos são estimados a partir de variáveis locais e / ou seus gradientes, Hu et al. (2010), ou se não fluxos locais são adicionados (fechamento não-local). Estes não-local os termos podem ser tanto parametrizadas ou tratados explicitamente.

\section{RESULTADOS E DISCUSÕES}

O WRFn simulou, de maneira bastante precisa (Figura 1), o comportamento das variáveis no período. A temperatura do ar apresentou correlação de 0,95 e erro quadrático médio de $0,46^{\circ}$ C. Estudos feitos por Hines et al. (2011) utilizando uma grade com $25 \mathrm{~km}$ de espaçamento horizontal, em Barrow, Alasca, encontrou índice de correlação variando entre 0,61 em julho (verão) e 0,91em dezembro. Para a temperatura do ponto de orvalho, a correlação foi de 0,73 com erro quadrático médio de $2,48^{\circ} \mathrm{C}$, mostrando ainda uma boa representação, mas inferior a de temperatura.

A pressão também teve excelente representação, com correlação de 0,99 e erro quadrático médio de 0,74 hPa, semelhante aos estudos de Hines et al. (2008) na Groenlândia e Bromwich et al. (2009) no Oceano Ártico. Finalmente, a intensidade do vento apresentou correlação mais baixa, de 0,62 , com erro quadrático médio de $3,6 \mathrm{~m} / \mathrm{s}$, com uma tendência maior de que o modelo subestimasse as observações. Esses erros podem ser atribuídos à rugosidade da superfície próxima à baia, onde o modelo não representa adequadamente as 
áreas de fronteira entre a baia e as encostas. Estes resultados estão em acordo com estudos realizados por Hines et al. (2011), no Alasca.
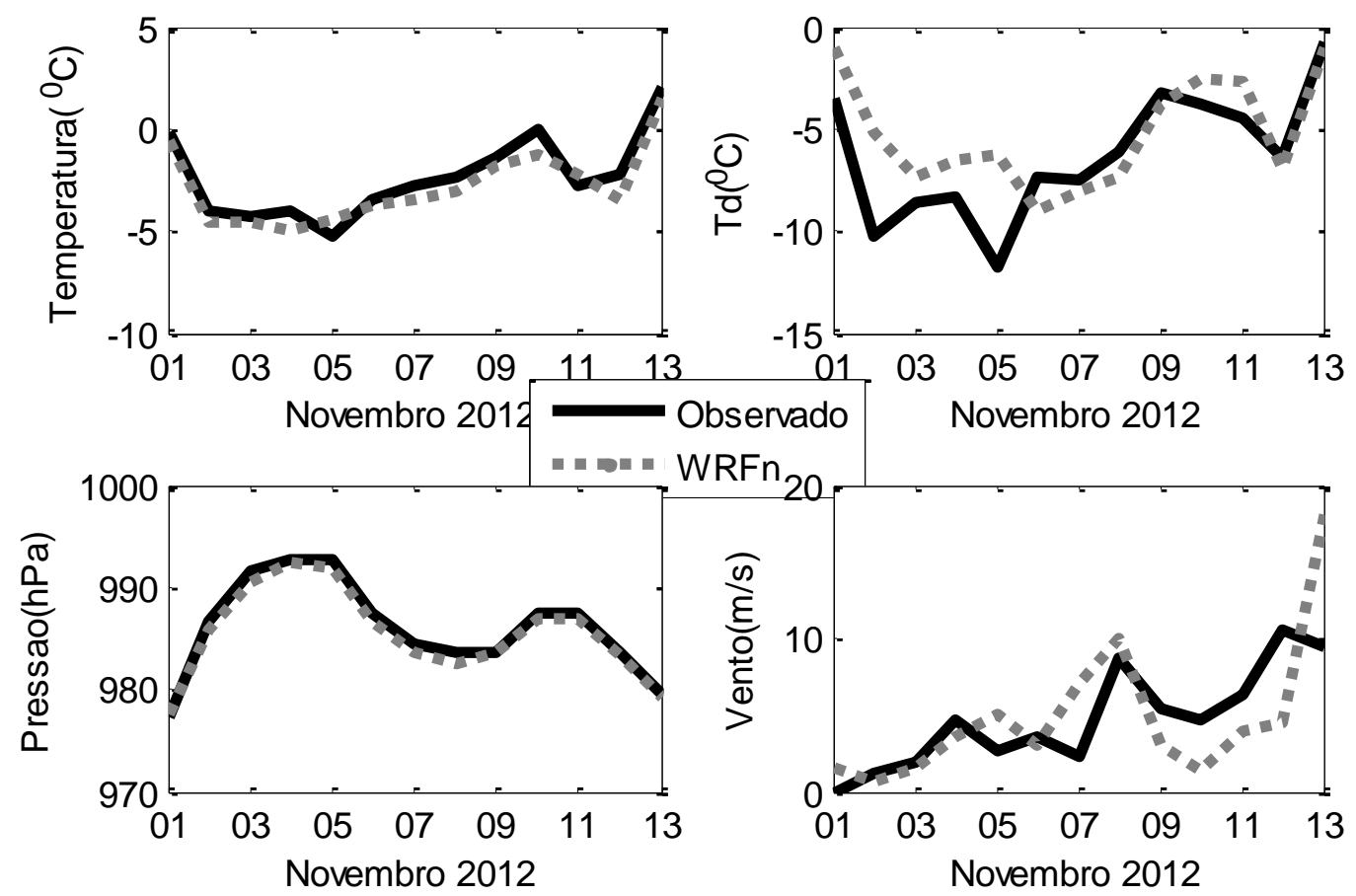

Figura 1. Medidas realizadas no interior da baia Deception durante o período 1 a 13 de novembro de 2012. A linha preta continua são os dados observados e a pontilhada a saída do WRFn.

\section{CONCLUSÃO}

O modelo WRF apresentou os resultados mais fidedignos com a pressão atmosférica em superfície. Para a temperatura do ar, os valores simulados foram $1,1{ }^{0} \mathrm{C}$ inferior as observações. Essa sub-estimativa pode ser devido à influência de uma área de montanhas cobertas por neve próxima ao local das observações. Já o ponto de orvalho e a velocidade do vento tiveram as menores correlações 0,73 e 0,62 respectivamente. Esse trabalho mostra que o WRFn poderá ser usado em pequenas áreas com uma boa precisão dos parâmetros atmosféricos. Para isso, tem que ser utilizado espaçamento da grade interna maior do que a dimensão da área de estudo, devido aos fortes gradientes térmicos nessas pequenas ilhas, que poderão ocasionar erros significativos nas temperaturas do ar e no ponto de orvalho.

\section{AGRADECIMENTOS}

Este trabalho foi financiado por Capes/CNPq. 


\section{REFERÊNCIAS BIBLIOGRÁFICAS}

BROMWICH, D. H.; HINES, K. M.; L.-S. BAI. Developments and testing of Polar Weather Research and Forecasting model: 2. Arctic Ocean, J. Geophys. Res., 114, 2009.

HINES, K. M.; BROMWICH, D. H. Development and testing of Polar WRF. Part I: Greenland Ice Sheet meteorology. Mon. Wea. Rev., 136, 1971-1989, 2008.

HINES, K. M., BROMWICH, D. H., L.-S. BAI et al. Development and Testing of Polar WRF. Part III: Arctic Land, Journal of Climate v24, 26-48, 2011.

HU, X., NIELSEN-GAMMON, J. W.; ZHANG, F. Evaluation of Three Planetary Boundary Layer Schemes in the WRF Model, J. Appl. Meteorol. Climatol., 49, 1831-1844, 2010.

JANJIC, Z. Nonsingular implementation of the Mellor Yamada level 2.5 scheme in the NCEP Meso model, NCEP Office Note 437, p. 60, 2002. 